\title{
The Civil Society Organization Media Manager as Critical Communicator
}

\author{
Peter Lemish \& Kelly Caringer ${ }^{1}$
}

\begin{abstract}
Substantial improvement in civil society organizations' [CSOs] management of communication and media endeavors requires a shift from business and marketing models to a development communication perspective. Acting beyond the platform driven model of the current conception of the media manager, the critical communicator will be guided by a rights-oriented, civil society-driven social change vision; critique of the corporatization and marketization of CSOs; lateral, holistic management strategies in facilitating the efforts of the communication - media team; use of multiple media including new media technologies, in particular Web 1.0, 2.0 and 3.0, in order to advance audience-user participation in knowledge production and dissemination [participatory informatics]; and media campaigns that seek to maximize the CSO's contributions to the advancement of justice, equality, democratization and civic engagement in governance and public policy debates.
\end{abstract}

Keywords: civil society organizations, critical communicator, participatory informatics

\section{Introduction}

The recent wave of mass citizen-driven initiatives - beginning with the Tea Party Movement and continuing through the Arab Spring and evolving global iterations of the Occupy Wall Street Movement - demonstrate, once again, the vibrancy, dynamism and potential of civil society to take consequential roles in developing the character of our societies and quality of our lives. Power relations were shifted in the US Congress, autocratic regimes were toppled in Arab states, elections were disputed in Russia and significant political, economic and ecological issues were debated in local, national and global public spheres. These processes also strengthened civil society via engagement of multitudes of citizen-members whose voices were communicated via human megaphones, text messaging and town hall meetings, as well as mass, alternative and new media. While these accomplishments are filled with promise, realization of significant changes in political, economic, judicial and ecological structures requires sustainable efforts by citizens and civic groups, including local, national and global civil society organizations [CSOs].

CSOs per se have not been at the forefront of these recent events. However, we submit they can serve as one of the key civil society institutional mechanisms for realizing the potential of citizens to play increasingly important roles in governance, policymaking, 
oversight and agenda setting, as well as sustaining civic engagement and ground-up efforts to advance change. This article will focus on two of the key improvements in CSO functioning needed to realize such potential: First, development and management of multiple communication-media strategies; and second, participatory informatics that facilitate collective production and distribution of knowledge.

Our discussion here of CSO communication-media activities developed via an ongoing action research project aimed to inform our college's initiatives in CSO communication and media management. This was deemed necessary due to the paucity of empirical and conceptual studies that enable us to understand communication efforts within the expanse of CSO involvement in global civil society. Accordingly, this article seeks to contribute to the conceptualization of CSO communication and media endeavors that we hope will evolve through our own and others' engaged scholarship and praxis. To this end, we will present selected findings from our ongoing empirical studies of CSO communication and media efforts, with a focus on the potential contributions of participatory informatics to strengthen civic engagement and support vibrant debate of policy options and governance in the public sphere.

We argue that persons involved in communication-media work should be conceived as communicators, in opposition to the narrow technical role of media/platform managers. We also argue that conceptualization should account for different paradigms available for communication-media endeavors, as the professional orientation adopted by a CSO Communicator determines the nature, scope and impact of the CSO's communication and media endeavors. Thus, communicators with a marketing orientation will tightly control message and information diffusion, as well as engage in branding and managing advertising campaigns. In contrast, a critical communicator imbued with a development communication orientation ${ }^{2}$ will be guided by a rights-oriented vision, advance participatory knowledge production and dissemination and create media campaigns related to justice, equality, democratization and civic engagement in governance and public policy debates.

\section{Problematizing Current Conceptualizations}

The need for conceptualization is most evident in organizational signifiers. Since commonly used terms such as nongovernmental (NGO), nonprofit (NPO), voluntary, third sector and development communication make no direct reference to civil society, which is a primary audience of such communication efforts, we prefer the term CSO. Furthermore, references to NGOs and NPOs employ dualistic distinctions that do not capture the essence, mission, range of activity or contributions of CSOs (Frumkin 2002), which are neither fiscally nor governance-oriented. For example, distinguishing between governmental and non-governmental organizations can lead the uninformed to assume that CSOs are not involved in the provision of government services; although this has become a key surrogate activity for many CSOs awarded government contracts (Boris 2011). Indeed, corporate and governmental forces are also playing a dynamic role in shaping and conceptualizing the nature and character of CSOs (Eikenberry \& Kluver 2004). This is done via strong incursion of business-corporate management models, framing CSO initiatives as social entrepreneurship (Neff \& Moss 2011), financing via government contracts (Cone 2011) and tax-reduction driven corporate social responsibility and nar- 
rowly conceptualizing CSO communication work as management of media platforms or marketization (Eikenberry \& Kluver 2004; Wymer \& Mottner 2009).

In our view, the spirit and mission of critical development communication discourses should be adopted by those CSOs committed to advancing democratization and rightsoriented social change (e.g., Huesca 2003; Melkote 2003; Mercer 2002; Moore 1995; Quebral 2001; Wilkins \& Mody 2001). However, such an orientation is not nearly inclusive of the entire spectrum of CSO interests and activities. Indeed, for well over one hundred years, much local, national and global CSO activity has served and supported the existing order by seeking to conserve or advance religious and class interests, or advance total infusion of neo-liberal ideology into power relationships and the already well-established neo-liberal hegemonic order (Cone 2011; Eikenberry \& Kluver 2004; Frumkin 2002).

\section{Rationale for Signifier - 'Communicator'}

Some may argue that the position of $\mathrm{CSO} / \mathrm{NGO} / \mathrm{NPO}$ Communications or Media Manager/ Director/ Officer is synonymous with, or an expansion of, the role commonly referred to as press / public relations / public affairs officer or spokesperson. However, our research findings suggest that CSOs require a communication professional whose vision, commitments, understandings, approach, skills, sensitivities and successes are inclusive of, but qualitatively different from the role of spokesperson, press officer, social marketer, media manager or new media expert. Our findings suggest that persons in this role require a much broader professional approach than function-oriented management of numerous media platforms that distribute tightly constructed and controlled messages, stories and information. This broader view and the development communication spirit of this role, was captured succinctly in Dagron's (2004/2009) definition of the "new communicator", which we prefer be shortened to communicator:

The new communicator has the capacity to navigate from one media to another, to choose between multiple communication tools and adapt strategies to a particular situation. [...] [but he or she] must be equipped with the understanding that technology is a tool and nothing else but a tool. [...] Social change deals essentially with culture and a very special sensitivity is needed to support the process of social change [... and that $]$ in communication with the people and the communities the process is more important than the products [... since it] is in the process of communication and participation that social change starts to happen.

\section{The Functions of a CSO Communicator}

Findings from the initial stage of our action research project that investigated the role, responsibilities and qualifications of the CSO Communicator support this broader conceptualization. In this study, we selected 100 advertisements posted on www.idealist. com $^{3}$ : 70 were selected in December 2010 using the key words media, communication, manager, officer and director. Another 37 were selected in March 2011 on the same website using the key words advertising, marketing and public relations. After dismissing seven ads deemed unsuitable, the final corpus consisted of 50 advertisements for 
CSO positions in the United States and 50 worldwide. Content analysis was conducted inductively by both authors (i.e., no predetermined categories were employed; rather they emerged as we analyzed the ads). Inter-rater reliability was monitored and improved by conducting four emergent analysis rounds ${ }^{4}$.

\section{Overview of Key Findings}

First, only a few of the ads seek candidates with CSO experience or commitment to and knowledge of the organization's mission and domains of activity. Furthermore, language used in defining the desired qualifications of candidates for these positions and describing the communicator's duties and responsibilities does not seem to reflect a deep understanding of the organizational culture, mission, achievements and potential impact of CSOs. Additionally, no reference is made to the leadership role of the CSO Communicator, knowledge of social change or campaign processes or developmentoriented visions and priorities. Rather, the language used describes multiple tasks undertaken in a complex organization, framed through media [understood as platforms], marketing and business models of for-profit institutions. Thus, media managers are deemed responsible for planning, implementing and assessing a media plan; designing and implementing branding campaigns; managing media production and the entirety of media operations; and communicating with the press, organization members, funders, corporate sponsors and so forth.

Second, we found that most of the jobs advertised fit into one of two categories that we refer to as generalists and specialists. Generalists work at the hub of internal and external organizational activities in mid- to large-sized organizations, together with the organization's CEO. General management and media work are undertaken by the same person in small CSOs, occasionally with assistance from another staff member or volunteer (as in the case of Green Spaces, below). The generalist manages multiple communication streams with the organization's different audiences (e. g., diffusing internal memos, press releases and other media relations, website and social media coordination, impact reports, donor newsletters, volunteer recruitment and communication, issue-oriented public education and research reports). On the one hand, the language used to define the qualifications as well as duties and responsibilities of these media managers is most similar to business administrators. On the other hand, the sheer number of tasks, as well as their variety and breadth, demonstrates the complexity of generalist job descriptions. The composite view can be conceptualized as a call for a communication generalist with a wide breadth of skills and familiarity with nearly every medium; a manager who can strategically leverage information and staff to increase the visibility of the organization's brand; and a multi-tasker with capabilities to manage multiple communication streams for diverse audiences, create and manage content and strategically develop messages and media plans. For example:

This is a key senior management position. The lead Communication Officer plays a key role in the development, management and implementation of X's communications strategy, activities and team ...multi-function entrepreneurial is responsible for strategic planning, management and liaison; institutional communications, program communications, media coordination, events and seminars, online communications. [Ad 26] 
In contrast, specialists, mainly new media specialists in the ads analyzed, are often expected to bring new tools to media endeavors ${ }^{5}$. The search for the new media specialist appears to be driven by unfamiliarity with new technologies among the CSO's existing media staff, as well as what appear to us to be exaggerated expectations of the seemingly omnipotent and omnipresent capacities of social media networks. In concrete terms, the new media specialist is called upon to retrofit an existing operation with the latest technology to reach a broader membership base and, in some cases, to manage web analytics. For example:

\begin{abstract}
$\mathrm{X}$ seeks an intelligent, conscientious, motivated team player to serve as our Web Coordinator... responsible for formatting and posting online content, developing new web sections, pulling web analytics, organizing web projects and updating social media channels such as Facebook \& Twitter ...provides support to Web \& SM Manager and plays an important role in dynamic, fast-paced web \& communications team. [Ad 18]
\end{abstract}

Third, the emergence of a professional management track with progression from line employees to managers is discernible. These tracks are primarily distinguishable by the qualifications sought (e. g., the nature of CSO media-related experience, as well as the roles and responsibilities for different management domains and tasks). Line employees are less experienced CSO media employees who focus on well-defined projects and campaigns of limited scope, production and management of specific media platforms and the organization's media products. They report to a manager, work in teams on assigned tasks in accordance with the organization's media plan and are expected to have three - five years of media-related experience. Managers head the CSO's media department; supervise its staff; carry out executive decisions; report to the CEO and Board; and develop, implement and evaluate the CSO's media plan.

While findings from our ad research support the general trends of professionalization of CSO staffs, marketization and assessment-driven philanthropy, we do not believe these formal statements capture the rich, dynamic nature of CSO communication and media endeavors. Our claim is illustrated below via selected findings from two ongoing qualitative studies: interviews of CSO Communicators and analyses of CSO websites.

\title{
Dynamics of CSO Communication - Media Endeavors
}

The following exemplars from our research demonstrate the dynamic, varied nature of CSO communication-media activities and contributions to civil society and provide us with immediate grounds to argue for the need to conceptualize these endeavors:

- Green Spaces [anonymous], a land conservancy CSO active for nearly 40 years in a Midwestern town in the USA, has 200 members and owns/manages six open space parcels. The Executive Director (half time, employed for seven years) is the CSO's only employee. She listed the following as her primary responsibilities in our interview: managing daily operations and finances; implementing Board decisions and distributing minutes; organizing and advertising monthly work days and special projects; writing materials for and maintaining the website and quarterly newsletter; and, applying for grants. A former natural resources researcher, she had no previous experience in managing a CSO or with any manner of media production, including work with websites. 
- The unannounced implementation of a biometric identification system for improving efficiency in a local U.S. elementary school cafeteria's lunch lines provoked the second author to initiate a school-parent communication initiative. Conducted primarily via social media technologies, this project seeks to foster the exchange of information and views about privacy issues related to institutional use of biometric identifiers. The aims of this initiative are to: increase opportunities for community dialog, share knowledge regarding privacy legislation and advance conflict management efforts. The latter is necessary given that potential lawsuits by the parents of as many as 750 affected children could, if successful, bankrupt the school district due to presumed violations of a state law requiring public knowledge of and consent to use such technologies prior to their introduction and the costly, statutory penalties for each privacy violation. The author's research intention is to document attempts by this loosely organized, media-driven, community initiative as it seeks to advance conflict transformation and social change.

- A media activist in the worldwide Falun Dafa Movement cited that the pivotal roles of communication systems and media platforms in advancing their aims are: to provide the world with evidence of the Chinese government's oppression and violation of practitioners' human rights and to support Falun Dafa adherents in China and worldwide. The movement has done so without a formal organization, staff and consequently media managers. Rather, hundreds of volunteers - inside and outside of China - are involved in gathering, producing and distributing information via multiple media platforms, including - print and online newspapers, websites, posters and other print materials, pamphlets distributed at demonstrations, cultural performances, streaming news to Chinese citizens, counter-acting Chinese surveillance and cyberattacks and more - often at considerable risk to their own lives and careers.

Following Servaes's (2008) discussion of the diffusion and participatory communication models within the field of development communication, Green Spaces is representative of the Diffusion Model that we found in our studies to be the most prevalent approach to NGO media activities: Monologic communication to Green Space's Board, members and the general public is controlled and managed by the executive director. In this process, the Executive Director/media manager employs various media platforms to dispense tightly designed and formulated information via newsletters, minutes, press releases announcing public events, publicity campaigns, direct mailings and membership drives. The Green Space's internet website employs basic Web 1.0 technology that neither allows user interactivity with the website nor inclusion of embedded hyper- or interactive texts. A recently added Facebook page does allow some public response, as do email exchanges, largely with the $\mathrm{CEO}$, related to activity information.

In contrast, the second and third examples are representative of development communication's Participatory Model (see also Huesca 2003) in which communication systems, media platforms and various communicators facilitate information sharing and interactivity between multiple organizational and civic participants, in general and in communication and media efforts, in particular. The joint school-parent website initiative seeks to involve all parties to the conflict via a shared media platform in order to encourage communication between all of the parties, to make available information and opinions from multiple sources and to lead a process of conflict transformation in 
the civic arena that involves government [school] and commercial [biometric company] bodies. This approach is consistent with the participatory interest in fostering civic engagement and democratic-oriented social change. From the Falun Dafa case, we learn that multiple, de-centralized communication and media efforts are advanced not only by members of the movement worldwide, but also dialectically by the Chinese government, whose opposition efforts and interventions stimulate both sides to employ advanced media technologies for communication.

As a key CSO communication-media task, information management differs in these two models. The tight control of the Diffusion Model is particularly appropriate to CSOs and communicators applying business-management and marketing orientations. In contrast, according to the Participatory Model, we learn that the critical communicator exploits the capabilities of all available communication systems, media platforms, personnel and audience-participants to facilitate engagement of multiple audiences and advance development-oriented, civil society-based change efforts. In order to enrich our understanding and conceptualization of the potential of participatory-oriented CSO information management, we have directed our inquiries into the evolving field of community informatics, as detailed in the next section.

\section{Empowering Communities through Informatics}

In our effort to preserve the spirit of development communication discourse while suggesting a broader conceptualization of CSOs and their activities, we stress, in this section, the importance of harnessing tools that connect and empower people, as well as collective production and effective dissemination of knowledge in accordance with advocacy goals. Our analysis is guided by Nora C. Quebral's observation: "the processes by which these goals are achieved are just as important for the outcome as the goals themselves" (2001: 4). Thus, in the second phase of our research, we are investigating the ways in which new media are being employed by CSOs and the implications of introducing new information and communication technologies [ICT] into existing communication models.

While new ICTs can be applied internally to improve organizational efficiency or to embellish diffusion communication strategies, we submit that their greatest potential lies in the potential to link CSOs and various audiences in a variety of ways. Such linkages enable dialogic / two-way communication flows, management of large volumes of available information and facilitation of civic engagement (e.g., Bennet 2008; Dahlgren 2007; O'Reilly 2005). Employing ICTs to realize such potential should constitute, we submit, a large part of a CSO's informatics strategy.

From among the various usages of the term "informatics" (see Gurstein 2000; Sawyer \& Rosenbaum 2000), our usage refers to the process of applying information and communication technologies and/or critically assessing their impact within a social, cultural or institutional context. Thus, while CSOs are often influenced and/or managed by pervasive corporate management and communication models, a development-oriented participatory informatics approach would enable the critical communicator to counter these models by implementing ICTs in ways that enable civic engagement, sustain the organization, as well as increase program efficacy and revitalize the spirit of development in civil society. Sophie Treinen wrote recently about such an approach: "The human 
factor in civil society information and communication systems is crucial because the needs of the people should be at the heart of any system" (2010, p. 40). Accordingly, a CSO critical communicator implementing a participatory informatics-orientation (our proposed signifier) will evaluate the social potentialities of ICTs and implement a strategic plan to advance the mission of the CSO via development communication. In the discussion below, we posit a number of key issues and actions involved in this process.

\section{Of Tools and Technologies}

The World Wide Web, once a vast accumulation of isolated web pages, is rapidly cohering into a purpose-built, data-driven, user-centered network of information. The widespread public use of online social software like Facebook, Twitter and YouTube has greatly increased the capacity of CSOs to connect with members (Greenberg \& MacAulay 2009). The emergence of these new tools of connectivity and their potential to transform online social interaction inspired Tim O'Reilly to coin the term "Web 2.0" to describe them (O'Reilly 2005). According to O'Reilly, Web 2.0 marks the beginning of a global Internet operating system that serves less as a parking lot for disjointed web pages and more like a system for combining knowledge into a global compendium. Web 2.0 users not only access information online, they interact with and contribute to it. Thus, knowledge produced at local, national and global levels can more easily be exchanged in a shared context, facilitating participation across geographic boundaries in real time. As we enter the era of Web 3.0, data sets can now be cross-referenced between two or more URLs ${ }^{6}$, allowing multiple organizations to exchange raw statistical data and research findings, or enabling automated processes that compile relevant information from a multitude of disparate sources. Such capabilities can enhance CSO efforts to engage in public education, advocacy and sharing of views by linking tributary organizations and users worldwide.

However, a gap remains between future possibilities and present realities of webbased communication tools used by CSOs. In our research we found that many CSO Internet sites have yet to fully engage Web 2.0 (see also Greenberg \& MacAulay 2009); that is, they employ Web 1.0 exclusively. In such cases, the Internet is employed via the same monologic communication modes used to diffuse information (e. g., distribution of press releases or mailing the organization's brochures and membership newsletters via the post office). These sites often employ similar organizational templates, aesthetic designs and top-down communication models, following the printed page metaphor of Web 1.0. While our explanations for this disparity are largely conjectural at this stage, our research of CSO job advertisements found reliance on for-profit business and marketing-oriented communication models that are largely monologic in orientation and may have a limiting effect on strategies used and technologies employed by CSOs to engage their publics. A second finding from our ad analysis that may offer an explanation is the frequent call for "new media specialists" or "social networking experts" who are sought by CSOs to retrofit existing communication strategies with the latest technologies. Here, a focus solely on the technical aspects of new ICTs risks neglecting the social advantages of a well-connected, mobilized public.

Fuchs, Hofkirchner, Schafranek, Raffl, Sandoval \& Bichler (2010) suggested that a sociological taxonomy of Internet technologies such as Web 1.0, 2.0 and 3.0 differentiates them without a sole focus on their technical peculiarities. In their broader view, 
each 'Web' capacity is indicative of characteristics that enhance human cognition, communication and cooperation. According to Fuchs et al., all cooperation processes require both cognition and communication, though not all processes of cognition and communication result in cooperation (2010: 43). Recalling our earlier quotes by Quebral and Treinen, this insightful observation decenters the technologies themselves to account for the techno-social processes through which participants act in civil society. In the near future, the development-oriented critical communicator may seek integration of ICT software tools because embracing all three technologies may best position a CSO to facilitate civic engagement. Thus, knowledge (Web 1.0) and discourse (Web 2.0) will be combined with use of Web 3.0 to facilitate cooperation and collaboration among participants who share an interest or goal. Future studies may then determine if such an approach has the greatest chance to realize the potential of CSOs to contribute to civic engagement and democratization.

This analysis points to the crucial role of the communicator in leading the CSO to select and implement technological means toward achieving social ends. We submit that the critical communicator will do so by facilitating cooperative, participatory communication through use of higher-order, technologically enhanced strategies of participatory informatics.

\section{Facilitating Civic Engagement}

Social networking tools make it possible for users to participate in many-to-many communication flows in contrast to the one-to-many broadcast, diffusion communication model. Not only can users (i.e., CSO members and other media audiences) exchange comments and messages inexpensively and efficiently, they have the capability to create and exchange content/knowledge. This change in cultural production and social communication has already impacted commerce and politics. For example, increased userconnectedness allows news stories and political action initiatives to develop collectively and influence groups of people with unprecedented speed and scale. News feeds, "likes" and shared posts increase the salience of products and issues as they reach an expanding audience (Bennett 2008).

Our research found that CSOs are well aware that tapping into the popular use of social software can increase CSO visibility, advance philanthropic endeavors, as well as recruit and reach target audiences. However, given the plurality of ICT capabilities, we ask if they are also considering how developments in new media can enable them to facilitate members' active participation in advancing a CSO's mission?

Simply linking an official CSO website to a Facebook page neglects the possibility of engaging users on a deep and meaningful level. Used imaginatively, social software has the potential to build community and facilitate participation. For instance, while the International AIDS Vaccine Initiative has a parallel web presence and Facebook profile allowing visitors to receive updates and spread the word about the organization's activities, Save the Children goes one step further. A "Take Action" tab on the Save the Children website guides users through an interactive letter-writing process that contacts the user's representatives in the U.S. Senate. While the former organization aims at increasing online awareness of issues, the latter aims at mobilizing users so that they act as a catalyst for civic engagement. Save the Children's hybrid Internet strategy harnesses 
social media to expand membership and promote issue awareness, while facilitating activism using standard HTML code and a series of basic text fields. Thus, successful blending of Web 1.0 and 2.0 characteristics directs our attention away from the technology itself and onto the social processes of communication and civic engagement.

In consideration of the degree to which ICTs have penetrated many populations, the role of CSOs is becoming increasingly important as governments worldwide struggle to provide the public services expected by citizens (Janssen \& York 2006). Even outside the scope of CSO activity, citizens throughout the world are embracing social media and mobile technologies in particular, to express their dissatisfaction with bureaucratic governance through a process that Richard Grusin calls "premediation”. Grusin posits that "premediation works by mobilizing affect in the present... preparing people for some field of possible future actions" (2011: p. 3).

The collective sentiment and worldwide stirrings referred to at the beginning of our article indicate the emergence of an era of possibility for CSOs to lead citizens united in voice and seeking opportunities for collective action. For this reason, we claim that a critical communicator will understand the value of empowering an engaged public through the creative use of ICTs to bring about democratization and social change and therefore will advance use of a participatory informatics approach designed to facilitate civic engagement.

\section{Data Management}

Even as CSOs seek to take full advantage of Web 2.0 and so increase member connectivity and facilitation of dialogic modes of communication, they may well lag behind the rapidly emerging Web 3.0 that also has the potential to advance development-oriented information management (Berners-Lee 2001; Miller 2004; Smith \& Miller 2011). Also referred to as the semantic Web, Web 3.0 is sometimes described as the process of enabling machines to understand the meaning of data found on the Internet. This data can be manipulated in various ways - some that benefit humans and others that advance special interests and power relations. We see this second type of functioning today in the commercial sector when software are employed that collect personal information and behavioral characteristics of Internet users in order to deliver "relevant" advertisements tailored individually. Since competing sectors of society are able to leverage technology to achieve different ends, the definition of Web 3.0 put forward by Fuchs et al. (2010) reminds us that, contrary to the purely technical interpretation, Web 3.0 is simply a characteristic of the World Wide Web that enhances cooperation between people and technology in ways that further civic engagement.

Although we found few examples of Web 3.0 among CSOs, there are exemplary cases of data management that demonstrate such capabilities. For example, The Sunlight Foundation developed a series of applications that search for public information within various government databases. When compiled, this information makes it easier for the public to identify the sources of political contributions and levels of interest regarding federal and state level politics in the U.S. Because the applications' user interfaces are designed for ease of use and seamless incorporation into such daily activities as email and online news reading, structural barriers to knowledge regarding government operations are reduced. 
The American Dream Movement, or Rebuild the Dream, is a second example of a CSO successfully harnessing ICTs to mobilize its constituents toward collective action. The organization launched a "crowdsourced" effort in June 2011 to generate, collectively, a list of possible solutions to problems currently facing the United States. By way of a simple online user interface, the organization sought to advance cooperative civic action by inviting thousands of members to propose and deliberate about ideas and then select ten solutions that would become "A Contract for the American Dream".

These examples illustrate two innovative ways in which CSOs have used ICTs to connect people with information in order to have a positive impact on civil society and to advance civic engagement. As freedom of information legislation and popular demand for transparency in governance create opportunities for increased public knowledge worldwide, employing ICTs to gather, synthesize and make available large amounts of information from varied sources will likely become an important CSO communicationmedia activity. This, in turn, can contribute to increasing civic engagement and, via participatory informatics, in facilitating development of collective interpretations and action responses to such information.

Yet, all too often today the roles of information and communication technologies in society are shaped by corporate interests (Eikenberry \& Kluver 2004; Gurstein 2003). Our research indicates that as CSOs encounter and adopt ICTs, they often do so in accordance with popular conceptions of their current roles and potentialities, which happen to fit nicely within the business and marketing models of communication. Under these circumstances, web-based ICTs become part of a monologic, diffusion communication flow that limits or precludes participation among members and neglects possibilities for enhanced dialogic activity and collective action. In contrast, when CSOs harness ICTs to connect and empower people and facilitate shared production and distribution of knowledge that contributes to advocacy goals, they provide pathways for collective civic action and social change. Thus, a CSO critical communicator who applies a development communication perspective attempts to manifest these social potentialities and meet the challenges of employing ICTs to facilitate human contributions toward finding solutions to social issues.

We suggest that if CSOs are led by a critical communicator working through such a perspective when advancing participatory informatics in the design and implementation of a communication strategy, then a people-centered approach will be advanced that embodies the spirit and mission of development communication discourse. In our view, the efforts of such a critical communicator will greatly increase the capacity of the organization to achieve substantive gains toward meaningful social change and democratization.

\section{In Conclusion: Toward a Conceptualization of the CSO Critical Communicator}

Our overarching conclusion is that the CSO communication - media domain has the potential to play significant roles in strengthening the contributions of CSOs to civil society and society, locally, nationally and globally. However, realizing this potential should include conceptualizing the communication-media domain, in general and defining the roles of the critical communicator as generalist manager and leader of communication- 
media activities. This conceptualization process can be advanced by developing more extensive research projects and professional education programs.

In seeking to contribute to this process, we offer the following claims, ground in our ongoing investigations of current trends in CSO communication - media use:

1. CSOs should be viewed as among the leaders and contributors to strengthening citizen engagement in civil society and CSO communication-media endeavors should assume a central role in such efforts.

2. The concept of communicator as generalist captures the essence of the role of the person responsible for managing CSO communication systems and media production. The critical communicator will perform the role through lenses that enable him/ her to be critical of the corporatization and marketization of CSOs and informed by development communication praxis to advance democratization and ground-up social change efforts.

3. The dynamic, complex nature of the communicator's role calls for a holistic approach that integrates six different areas of expertise: organizational communication, CSOappropriate management and leadership, media production, marketing, informatics and creativity.

4. New media technologies provide CSOs with challenges and opportunities to realize their potential in providing civil society with rich sources of information in a relatively easy and accessible manner. Communicators should emphasize informatics management among the key aspects of a communication-media department.

Finally, to concretize these claims we propose a set of key aptitudes that can serve the critical communicator as generalist and CSO communication leader. These aptitudes, we submit, should be developed in CSO communication and media studies so that they are embodied by graduates.

- Praxis, defined operationally as actions conducted through critical understanding and moral judgment (Freire 1970; Lemish \& Schlote 2009), is the foundational process lens. With training, it promotes problematizing everyday social life, develops deepstructural understandings of social phenomena, encourages consideration of multiple criteria in reflecting on the moral dimensions of social issues and actions, develops intervention scenarios that lead to selecting the best option for advancing structural change and then follows implementation of the planned actions.

- Applying a holistic - historic perspective is essential for the communicator-generalist given the multiplicity of audiences and networks, their needs as well as those of the CSO, media platforms, messages, process and change components and outcomes. Therefore, this role requires developing and viewing the facilitation of internal and external communication holistically and historically, while probing and reflecting through the praxis process on the implications for future actions.

- People-centered, participatory communication should be developed that fosters agency and concientisation and enables CSO members and the public-at-large to be agents advancing their own vision of the social change needed as well as masters of communication processes. 
- Development of a horizontal/lateral management style fosters collaboration and democratic decision-making, values process as well as product and defines the roles of the Communicator as leader and facilitator.

- Vision-guided leadership is in concert with the CSO's mission, organizational culture and volunteer-base so that media staff both support and contribute to realization of the CSO's collective vision and ends-in-view.

- Participatory Informatics / knowledge management views communication-media management beyond one-way diffusion of information to see the CSO playing an important role in participant production and exchanges of knowledge. In doing so, CSOs link the academy to civil society and together with broad participation of members become an active presence in policy debates and social activism.

- Creativity involves seeing oneself and the role of Communicator as an opportunity for innovation. This infuses critical thinking and a deep understanding of the value and power of aesthetics with an ever-evolving spirit that reflects and improves pastpresent endeavors.

The gap between communication theory and practice in regard to the civil society sector requires extensive research, theorizing and discussion, including a focus on the role of the communicator. We view this as both a challenge and an opportunity. We are challenged by the complexity of the communicator's role, the conditional nature of conventional and new media technologies and the persistence of knowledge management strategies that direct communication efforts toward fundraising and top-down information flows rather than sustained community development and civic engagement in democratization and ground-up social change efforts. We are optimistic, however, because of new opportunities for transformative social action. Internet technologies are redefining the relationship between CSOs and the publics they serve, as well as the ways in which the public actively participates in democratic communication and self-governance. It is our hope that critical communicators, prepared for leadership roles in CSOs through an interdisciplinary educational program, will be well positioned to help revitalize the public sphere, where the agendas of advocacy groups and the concerns of individual citizens intersect.

\section{Notes}

1. Peter Lemish is affiliated with the College of Mass Communications \& Media Arts, Southern Illinois University (e-mail: peterlemish@siu.edu). Kelly Caringer is a doctoral candidate in the College of Mass Communication and Media Arts, Southern Illinois University Carbondale (e-mail: caringk@siu.edu).

2. Our signifier for such approaches in the literature as 'Communication about development and humanitarian aid' and 'Communication about democratic social change'.

3. After a review of other internet employment venues used by CSOs (e. g., Communication Initiative, Devnet, and OneWorld.net), Idealist was selected due to global reach and representation, format consistency and richness of the job descriptions.

4. Inter-rater reliability improved from $80 \%$ to $90-95 \%$ agreement over the last two rounds.

5. While only five ads in our research corpus sought media managers as marketers, per se, public relations, advertising and marketing skills were included among both generalist and specialist tasks.

6. Uniform (or universal) Resource Locator, i.e. the address of a World Wide Web page. 


\section{References}

Bennett, L. (2008) Civic Life Online. Cambridge. MA: MIT Press.

Berners-Lee, T.; Hendler, J. and Lassila, O. (2001) The semantic web. Scientific American. (Retrieved March 26, 2008).

Boris, E. et al. (2011) National Study of Nonprofit-Government Contracting. Washington, D. C.: Center for Nonprofits and Philanthropy, Urban Institute.

Cone \& Intangible Business (2011) The Cone Nonprofit Power Brand 100. Boston: Cone.

Dagron, A.G. (2004/2009) Communication for Social Change: The New Communicator. http://kerymedia. com/Alfonso-Gumucio-Dagron/articulos/comunicator.html (Retrieved April 15, 2010).

Dahlgren, P. (2007) Young Citizens and New Media: Learning Democratic Engagement. NY: Routledge.

Eikenberry, A. \& Kluver, J.D. (2004) The marketization of the nonprofit sector: Civil society at risk? Public Administration Review. 64:2, 132-140.

Freire, P. (1970 Pedagogy of the Oppressed. NY: Continuum.

Frumkin, P. (2002) On Being Nonprofit - A Conceptual and Policy Primer. Cambridge, MA: Harvard University Press.

Fuchs, C., Hofkirchner, W., Schafranek, M., Raffl, C., Sandoval, M. \& Bichler, R. (2010) Theoretical Foundations of the Web: Cognition, Communication and Co-operation. Towards an Understanding of Web 1.0, 2.0, 3.0. Future Internet 2010. No. 2, 41-59.

Greenberg, J. \& MacAulay, M. (2009) NPO 2.0? Exploring the Web Presence of Environmental Nonprofit Organizations in Canada. Global Media Journal - Canadian Edition. 2:1, 63-88.

Grusin, R. (2011) Premediation and the Virtual Occupation of Wall Street. Theory and Event 2011 Supplement. 14:4. http://muse.jhu.edu/journals/theory_and_event/v014/14.4S.grusin.html (Retrieved December $10,2011)$.

Gurstein, R. (2000) Community Informatics: enabling communities with information and communications technologies. Hershey, PA: Idea Group Pub.

Gurstein, M. (2003) Effective Use: A community informatics strategy beyond the Digital Divide. First Monday, 8:12. http://firstmonday.org/htbin/cgiwrap/bin/ojs/index.php/fm/article/ view/1107/1027 (Retrieved December 10, 2011).

Huesca, R. (2003) Participatory approaches to communication for development. In B. Mody (Ed). International and Development Communication. Thousand Oaks, CA: Sage.

Melkote, S. (2003) Theories of development communication. In B. Mody (ed.) International and Development Communication. Thousand Oaks, CA: Sage.

Janssen, M. \& York, A. (2006) The niche of non-governmental organizations in a changing landscape of citizens 'preferences. Unpublished mimeo. http://www.public.asu.edu/ majansse/pubs/janssenyork06. pdf (Retrieved December 10, 2011).

Lemish, P. \& Schlote, E. (2009) Media portrayals of youth involvement in social change: The roles of agency, praxis and conflict resolution processes in TV programs. In T. Tufte \& F. Enghel (eds). Youth Engaging with the World - Media, Communication and Social Change, Gothenburg, Sweden: NORDICOM, pp. 193-215.

Mercer, C. (2002) NGOs, civil society and democratization: A critical review of the literature. Progress in Development Studies. 2: 1, 5-22.

Miller, E. (2004) The Semantic Web. http://www.w3.org/2004/Talks/0120-semweb-umich/ (Retrieved October $25,2011)$.

Moore, D.B. (1995) Development discourse as hegemony: Towards an ideological history - 1945-1995. In D.B. Moore \& G.J. Schmitz (eds) Debating Development Discourse: Institutional and Popular Perspectives (pp. 1-53). NY: St. Martin's Press.

Neff, D. \& Moss, R. (2011) The Future of Nonprofits - Innovate and Thrive in the Digital Age. Hoboken, NJ: Wiley.

O'Reilly, T. (2005) What is Web 2.0 - Design Patterns and Business Models for the Next Generation of Software. http://assets.en.oreilly.com/1/event/28/web2009_websquared-whitepaper.pdf (Retrieved August 28, 2011).

Quebral, N.C. (2001) Development Communication in a borderless world. Paper presented at the national conference-workshop on the undergraduate communication curriculum, "New Dimensions, Bold Decisions", November 23, 2001, Continuing Education Center, UP Los Baños. Condensed version appeared in Glocal Times, 3, 2006 (http:/webzone.k3.mah.se/projects/gt2/viewarticle.aspx?articleID=40\&issueID=5; accessed December 10, 2011).

Sawyer, S. \& Rosenbaum, H. (2000) Social Informatics in the Information Sciences: Current Activities and Emerging Directions. Informing Science Special Issue on Information Science Research, 3:2, 89-95. 
Peter Lemish \& Kelly Caringer The Civil Society Organization Media Manager as ...

Servaes, J. (2008) Communication for development - approaches of some governmental and non-governmental agencies. Communication for Development \& Social Change. LA: Sage.

Smith, M. \& Miller, E. (2011) Exhibit 3.0 Part 1 - An Open Source Software Platform for Publishing Linked Data. http://semanticweb.com/exhibit-3-0-part-1-an-open-source-software-platform-for-publishinglinked-data_b22962\#more-22962 (Retrieved October 25, 2011).

Treinen, S. (2010) VERCON: The Virtual Extension and Research Communication Network. Agricultural Information Worldwide. 3:1, 39-43.

Wilkins, K. g. \& Mody, B. (2001) Reshaping development communication: Developing communication and communicating development. Communication Theory. 11:4, 385-396.

Wymer, W. \& Mottner, S. (2009) Marketing inclusion in the curricula of U.S. nonprofit management programs. Journal of Public Affairs Education. 15:2, 185-202. 